\title{
Article
}

\section{The epistemological chain in high-level adventure sports coaches}

Collins, L., Collins, D., and Grecic, D.

Available at http://clok.uclan.ac.uk/12422/

Collins, L. ORCID: 0000-0002-7478-1140, Collins, D., ORCID: 0000-0002-76010454 and Grecic, D. ORCID: 0000-0003-1487-8327 (2015) The epistemological chain in high-level adventure sports coaches. Journal of Adventure Education and Outdoor Learning, 15 (3). pp. 224-238. ISSN 1472-9679

It is advisable to refer to the publisher's version if you intend to cite from the work. http://dx.doi.org/10.1080/14729679.2014.950592

For more information about UCLan's research in this area go to http://www.uclan.ac.uk/researchgroups/ and search for < name of research Group>.

For information about Research generally at UCLan please go to http://www.uclan.ac.uk/research/

All outputs in CLoK are protected by Intellectual Property Rights law, including Copyright law. Copyright, IPR and Moral Rights for the works on this site are retained by the individual authors and/or other copyright owners. Terms and conditions for use of this material are defined in the policies page.

\section{CLoK}

Central Lancashire online Knowledge www.clok.uclan.ac.uk

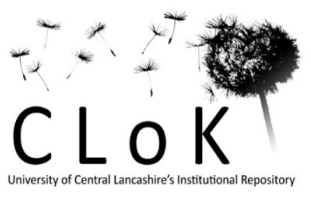


This is a pre-proof corrected manuscript, as accepted for publication, of a paper published by Taylor \& Francis in Journal of Adventure Education and Outdoor Learning on $26^{\text {th }}$ September 2014, available online:

http://www.tandfonline.com/doi/abs/10.1080/14729679.2014.950592

PLEASE REFER TO THE PUBLISHED VERSION FOR CITATION PURPOSES

The epistemological chain in high-level adventure sports coaches

Loel Collins*, Dave Collins and David Grecic

Institute of Coaching and Performance, University of Central Lancashire, Preston, PR1 2HE, UK

*Correspondence concerning this paper should be addressed to Loel Collins, Institute of Coaching and Performance, University of Central Lancashire, Preston, PR1 2HE, UK. Email: LCollins2@uclan.ac.uk. 


\begin{abstract}
This paper considers the personal epistemology of adventure sports coaches, the existence of the epistemological chain and its impact on professional judgment and decision-making. The epistemological chain's role and operationalization in other fields is considered, offering clues to how it may manifest itself in the adventure sports coach context. Highlevel adventure sports coaches were interviewed and an interpretive phenomenological analysis approach was adopted for the interview transcripts. Based on these data, we suggest that the epistemological chain provides the criteria by which adventure sports coaches measure the success of their coaching practice in the field and, further, that this epistemological chain also underpins the professional judgment and decision-making process.
\end{abstract}

Keywords: coaching; belief structure; professional judgment; decision-making 


\section{Introduction}

Adventure sports are big business, and this business is increasing. More than $7 \%$ of sports coaches in the United Kingdom are involved with adventure sports coaching (Sports Coach UK, 2011), servicing an estimated 150,000 climbers (British Mountaineering Council, 2003) and over 1,200,000 canoeists and kayakers (Royal Yachting Association, 2009), amongst other adventure sports activities. The demand for coaching is also a growth area, with a reported $48 \%$ of the UK population taking part in adventure sports at least once a year. There are a number of agencies involved in meeting the consequent need for more and, of course, better trained coaches: for example, the UK Coaching Certificate scheme (National Coaching Foundation, 2010) and the long-standing National Governing Body (NGB) coaching and leadership award schemes, such as the Mountain Leader Training Board in mountaineering and the British Canoe Union (BCU) coaching scheme in paddle sport.

Whilst these developments should be complementary, it may be that clarity is needed in relation to the exact needs of the adventure environment and its special demands. In short, whilst the role of the adventure sports coach (ASC) in a growing subgroup of sports coaching is clear, its place within a subgroup of established outdoor education and leadership is only now emerging. The challenge of integration is largely related to the multiplicity of roles which an ASC may fulfill. ASCs execute a complex role that includes leadership, personal development and performance development in challenging environments (Collins \& Collins, 2012). By necessity, due largely to the challenging and often hazardous environment in which they operate, these roles are underpinned by a technical ability in the field and synergized by a refined professional judgment and decision-making process (PJDM; Collins \& Collins, 2013). In previous papers, we have proposed that the

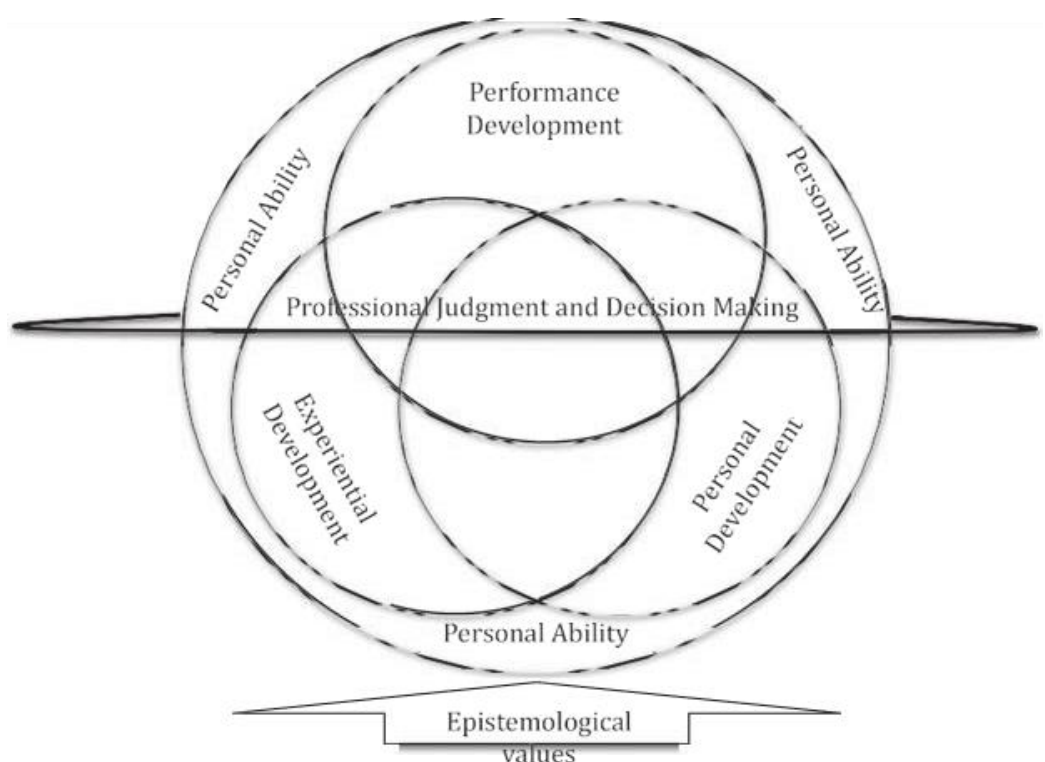

Figure 1. Epistemological beliefs underpinning the Adventure Sports coaching practice. Source: Adapted from Collins and Collins (2013). Decision making and risk management in adventure sports coaching. Quest, 65(1), 72-82. Reprinted with permission (http://www.tandfonline. com/doi/full/10.1080/00336297.2013.773525). 
PJDM process synergizes the different roles of the ASC. We propose in this paper that the PJDM is itself underpinned by a set of epistemological beliefs and ontological values, as illustrated in Figure 1. These epistemological and ontological structures act as the value system by which each coach will measure his/her own success. As such, these philosophical positions 'scaffold' the reflective practice that is critical in the PJDM and coaching process across sports (Grecic \& Collins, 2013). Specifically, the PJDM process relies on a structure of criteria against which judgments and planning can be measured and continually audited.

Given its importance, understanding and exploiting this structure is a key factor in optimizing coaching and coach development. Consequently, the value placed on intuitive decisions by the ASC (Collins \& Collins, 2013), the epistemological framework that underpins the ASC's practice and the link from belief to practice - the epistemological chain (EC), when offered as the criteria on which coaches plan, reflect and review (Grecic $\&$ Collins, 2013) - require further investigation. Of course, for any coach (general or adventure sports specific), the values that underpin the evolution of the EC are substantially influenced by previous experience. For example, Lorimer and HollandSmith's (2012) thematic analysis of an individual ASC revealed the impact of formative adventurous experiences over a long period, in-depth involvement with adventure sports, a desire to share a passion for adventure and a close sport/lifestyle interaction. Are these values and experiences shared with other ASCs? Do these experiences and beliefs contribute to what may be better described as an ontological chain? If so, would this represent a development of the EC, as proposed in relation to golf by Grecic and Collins? Reflecting these various considerations, we base this paper on the premise that how ASCs think is critical: thinking impacts on pre-planning, in-action refinement, emergency reaction and post-session review. In tracking the pathway of this thinking, together with how it evolves through development, we propose the EC as an essential construct enabling both greater understanding and more efficient development of the coaches' PJDM processes. Of course, this raises the question of its existence and impact. In short (and as the aim of this paper is to discover), do expert ASCs have an identifiable EC that can be recognized throughout their practice and, if so, can it be articulated? In addressing this aim, we will first outline the relevant theoretical constructs and their operational impact. Following this, we present an initial empirical examination of the existence and impact of the EC in a group of high-level ASCs.

\section{Personal epistemology and ontology—nature and impact}

It is worth considering the importance of these philosophical constructs for applied practice. Epistemology is important because it is fundamental to how we think, perceive, value and learn about knowledge (Perry, 1981). In turn, the ability to understand how knowledge is created, constructed, acquired and developed forms the foundation of our thinking and decision-making. On this basis, the link of epistemology and adventure sports coaching appears evident in the PJDM process, as it synergizes the differing functions of a practicing ASC (Collins \& Collins, 2012, 2013). The effect is even more far-reaching, however, with impacts on the aims, methods and evolution of the coaching process emanating from the coach's perceptions of knowledge. Ontological 'worldviews' relate to 
an individual's epistemological beliefs (Schraw \& Olafson, 2008) in relation to the nature of reality, which directly impacts on the value, control, certainty, nature, organization, application, creation and acquisition of knowledge.

The influence of these constructs on behavior is well documented. For example, Perry (1981) and Schommer (1994) highlighted epistemological development as a continuum, with beliefs being naïve or sophisticated at the poles. First of all, consider the naïve perspective, generally accepting knowledge as clear, specific, held in authorities and fixed. An ASC with a naïve EC would base knowledge on theory grounded in accepted prescribed models and reinforced by authority sources, such as training manuals, training courses and successful 'expert' instructional texts (cf. Ruse \& Collins, 2005) and testimonies. This belief is manifest in teaching strategies that ensure explicit learning takes place; defined practices that facilitate (apparently) rapid knowledge uptake. The coach owns the knowledge, manages its dissemination and is constantly required to provide reinforcement that generates a coach-dependent performance.

In contrast, the sophisticated view-that knowledge is complex, changing, dynamic and learned gradually via explicit cognitive processes - can be constructed by the learners themselves and therefore constantly developed (Howard, McGee, Schwartz, \& Purcell, 2000; Schommer, 1994). This growth may manifest itself in constructivist teaching strategies, randomized practice and problem-based learning with the intention of developing a performer's independence, self-analysis, reflection and lifelong learning. Such coaching practices would be supported through the use of coaching tools, such as delayed/ bandwidth feedback and questioning that encourages autonomous and independent performance. These coaches would question authority, engaging in performercentered coaching, which would encourage deep learning and understanding in their students.

Consideration of these two poles of behavior, naive or sophisticated, should suggest that the explicit consideration and development of the EC might offer some beneficial impact in the practice, training and development of coaches. As a further consideration, however, is this potential utility supported by applications of the EC construct in other domains?

\section{The genesis, impact and action of the epistemological chain in adventure sports coaching}

Highlighting the causal EC-behavior relationship, Grecic and Collins (2013) employed the concept of the EC as the related and connected decisions that are derived from personal beliefs about knowledge and learning, assuming a sophisticated epistemological belief structure. In the domain of golf coaching, Grecic and Collins noted that the EC becomes apparent in the planning processes, the creation of the learning environment, the actions taken and the coach's audit of performance. In turn, through their data, the EC was confirmed as a manifestation of the coaches' experience and establishment, whilst elements of it also acknowledged the external influences impacting upon the coaches' behavior. The EC was demonstrated as a consistent, logical relationship between philosophy, modus operandi, aims and session content at macro, meso and micro levels. Intracoach EC coherence (in simple terms, the consistency of this relationship) was found to be 
extremely strong. Extending these ideas, and in the present context of adventure sports coaching, with its highly specialized environmental context, an exploration of intra-coach coherence against an externally set EC specific to the outdoors would seem to be of great interest, with significant potential for understanding and enhancing coaching performance. At a personal level, an epistemological void (Collins, 2013) - the disconnection of belief and action - may be indicative of a developing belief and might even be desirable as part of the developmental educative process (Thorburn \& Collins, 2003); presumably, the generation of such cognitive dissonance contributes to the construction of a philoso- phical stance. However, epistemological voids between the ASC and the client/student, between ASCs working together in a team, between ASCs and employers, between ASCs and awarding bodies or between ASCs and policy-makers (cf. Collins, Abraham, \& Collins, 2012) may have significant implications for coherence, safety and practice in the field. Collins (2013) also comments that the epistemological void will be found where tacit knowledge is integral to an expertise. The value placed on tacit knowledge in ASC practice (Collins \& Collins, 2012, 2013) would seem to make ASC practice 'ripe' for this type of disconnect, and therefore indicates potential for development or confrontation.

In summary, it appears that there may be significant benefits in the application of the EC construct to adventure sports coaching. These extend from enhanced understanding of personal (intra-coach) working, through team-working and other interactions, to the design and deployment of optimally impactful professional training. Accordingly, we conducted an investigation with experienced ASCs to check for the existence of an EC in their practice.

\section{Method}

This paper utilized an interpretative phenomenological analysis approach (Smith, Flowers, $\&$ Larkin, 2009). A qualitative methodology was adopted to enable the breadth and richness of anticipated responses to be explored. In this case, the epistemological underpinnings of practice were considered by utilizing a semi-structured interview with high- level ASCs (see below). Given the interest and access of the first author, this initial investigation was completed in paddle sport.

\section{Participants}

A purposive sample of seven male British ASCs (mean age $=50.3$, standard deviation $=$ 9.1) was recruited based on the following criteria: holding multiple BCU Level Five Coach Awards and/or national coaching roles; actively engaged in ASC activity; active as an ASC educator; willing to unpack and reflect on their own coaching practice; well regarded by their peers; and availability. No incentive was offered and specific demographic information has been withheld to protect anonymity. Purposive sampling was used to ensure a seniority, experience and inherent quality (at least of self-reflection) in the participants in order to generate a picture of high-level performance. The participating coaches thus had a combined 157 years of adventure sports coaching experience in white water kayaking, sea kayaking, surf kayaking, canoeing, mountaineering, rock climbing, mountain biking and alpine skiing, enjoyed high-status reputations within the field and were all active as coach educators. In the absence of more effective or objective markers 
(cf. Nash, Martindale, Collins, \& Martindale, 2012) we were confident that this sample presented a picture of good practice.

The primary investigator and author has 25 years of experience as an ASC within the national centers in the United Kingdom, was a coach educator for the BCU and holds the BCU's Level Five Coach Award in four disciplines, as well as being a qualified mountaineering and skiing instructor. The researcher had a working rapport with the participating coaches. The second and third authors have extensive experience in adventure sports and coaching development/research and in coach education, respectively.

\section{Procedure}

The university's ethical advisory committee granted ethical approval and all participants provided informed consent. A single, semi-structured interview was undertaken at the coach's place of work to gain insight into the philosophy, ontology and epistemology of each participant coach. The interview focused on two broad areas: participant background; and philosophy in relation to adventure and coaching practice. An interview guide was constructed, piloted and adjusted prior to use with three similar qualified coaches. Nine general questions (Table 1) were used to scaffold the interview process, but these were not always utilized or asked verbatim depending on the breadth and depth of answers provided at the time. This approach allowed emergent themes to be explored, revisited and reconsidered. The empathetic, openly structured interviews varied in length (mean duration $=28.49$ minutes), and interviews were digitally recorded and transcribed using a commercial transcription service.

\section{Data analysis}

The text and audio were repeatedly reviewed in line with interpretative phenomenological analysis procedures suggested by Smith et al. (2009) and Smith and Osbourne (2008). Firstly, texts were read and corrected whilst listening to the original digital recording in order to be able to imagine the voice of the participants, facilitating a more 'complete analysis' (Smith et al., 2009, p. 82). During subsequent readings, these texts were reconsidered in terms of common, recurring and underlying phenomenological themes. As themes emerged, they were grouped and categorized into primary, secondary and tertiary as appropriate depending on the frequency of occurrence, relationship, context and content.

Table 1. Semi-structured interview.

\begin{tabular}{ll}
\hline Question & Probe \\
\hline Background & \\
& Experience \\
What do you feel are your key & Education background \\
qualifications & Training/continuing professional \\
and experiences that relate to your practice? & development \\
How long have you been a practicing & Sources of knowledge \\
coach? & Learning \\
What are the key attributes you have which & Observation \\
enable you to be an adventure sports coach? & Questioning \\
Are there any factors or characteristics that & Listening \\
\hline
\end{tabular}




\begin{tabular}{ll}
\hline limit & Information provided \\
your work? & $\begin{array}{l}\text { Perceived attributes and skills } \\
\text { Injury } \\
\text { Time management } \\
\text { Logistics } \\
\text { Conditions }\end{array}$ \\
& Experience \\
Philosophy & Education background \\
& Training/continuing professional \\
Why do you coach adventure sports? & development \\
What would be your overarching & Sources of knowledge \\
mission/initial & Learning \\
objectives of coaching in ASC? & Observation \\
How did you arrive at that decision? & Questioning \\
How has this evolved throughout your & Listening \\
career? & Information provided \\
What factors have influenced your & \\
approaches & \\
to coaching? &
\end{tabular}

To enhance the study's trustworthiness, and given the first author's experience in the field, bracketing was utilized. The researchers maintained a reflective commentary throughout the process, bracketing personal experiences and considering the influence of personal values (Smith, 2011a) during the interviews and analysis. The primary researcher, an experienced ASC, was aware that his relationship with the participants might influence the responses in interview. Firstly, the primary researcher's interest stemmed from a personal academic interest in ASC practice, its development and education. In particular, care was taken to ensure the interview was conducted in an informal setting of the participant's selection in a positive, respectful, friendly, collegiate environment and atmosphere using a collaborative approach. During the interview, as new avenues emerged they were explored and unpacked.

External and internal member checking was also utilized post-analysis to guard against misinterpretation and researcher subjectivity. A colleague (with no involvement with the research) acted as an independent investigator, thus providing an external check. The participating coaches and co-authors provided internal checks (Sparkes, 1998). In cases where this step identified a disagreement between members of the research team, each investigator re- read the original transcript and discussed the coding, and a consensus was agreed.

\section{Results and Discussion}

Initial analysis identified 490 individual codified units, which were subsequently grouped into 67 raw themes. These were collated into 13 lower-order themes (two of which were recurring) and then combined into four higher-order themes, as identified in Table 2. In line with Smith (2011b), we have provided examples from at least 50\% of the sample and have used quotes to demonstrate the depth and richness found in the data-in particular, the specific interaction of these higher-order and lower-order themes.

Table 2. Analysis of interviews. 


\begin{tabular}{|c|c|c|}
\hline Higher order themes & Lower order themes & Raw data themes \\
\hline \multirow[t]{9}{*}{ Positive Adventure } & Positive impact of challenge & Adventure \\
\hline & & Challenge and risk \\
\hline & $\begin{array}{l}\text { Personal Experiential } \\
\text { learning }\end{array}$ & $\begin{array}{l}\text { Learning from Miss- } \\
\text { adventure }\end{array}$ \\
\hline & & Learning from errors \\
\hline & Reflection* & $\begin{array}{l}\text { Recognition of errors/ } \\
\text { mistakes }\end{array}$ \\
\hline & & Use of risk-benefit \\
\hline & & Pattern recognition \\
\hline & & Decision making \\
\hline & & Anticipation \\
\hline \multirow[t]{8}{*}{ Independent performer } & Information gathering & $\begin{array}{l}\text { Questioning to develop } \\
\text { understanding }\end{array}$ \\
\hline & & $\begin{array}{l}\text { Continual Observation of } \\
\text { performance }\end{array}$ \\
\hline & & $\begin{array}{l}\text { Observation of individual } \\
\text { behaviour in coaching } \\
\text { context }\end{array}$ \\
\hline & & $\begin{array}{l}\text { Constant auditing of } \\
\text { performance via } \\
\text { Observation and } \\
\text { questioning }\end{array}$ \\
\hline & Learning and learner centred & Coaching environment \\
\hline & & Trust and Respect \\
\hline & & Long term Learning \\
\hline & Developing Decision making & Student centred \\
\hline
\end{tabular}


Psychological aspect of performance

Learning skills for personal development

Life Long Learning

"Make coach redundant"

Knowledge sources
Community of practice*

Adventure experiences

Pedagogic experiences
Peer support

Friends, family

Personal experience of adventure

Breadth of adventurous experiences and sports

Breadth of Environments

Life-long involvement with and belief in Outdoor Education

Personal Experience of coaching and being coached

Breadth of coaching experiences

Mental models of coaching

Learner centred

Allowed independence

Development of practice

Flexibility in response to 
environment, people, task

Reflection*

Understanding of personal ability

Recognition in value of adventurous experiences

In action and on action

Reflective practice

Value of challenge and risk

Understanding the Environment and it interaction with people and performance.

Critical of own performance

Self-measurement

Reflectivity

Check and Challenge

Development of selfanalysis skills

Sceptical

Challenging the status quo

Questioning of self and others Development of learning skills

Transferability

Understanding of

Questioning of knowledge environment, individual, task interaction

Technical understanding 
Own Mental model

Personal learning, experimentation in sessions

Adaptability and flexibility Reflection*

Community of practice*

Continuous Professional

Development
Adaptability in response to environment and people

Anticipation of development based on a mental model

Adaptability of performance and learning

Professional Development of coaching and personal skills

Reluctant expert

Interaction with Peers, socially and professionally

Reputation

"To be the best"

Reflection

Success

Learning new things

Credibility

Commercial challenge

\section{Positive adventure}


Participants in the study all advocated a positive view of risk, challenge and adventure within the pedagogic process. This epistemological view recognized the formative impact of a long, ongoing exposure to 'adventure' from childhood and may be better viewed as an ontological position. In turn, this ontological position was seen as contributing to the sophisticated epistemological view (cf. Schommer, 1994) held by the ASCs. This position mirrors that of 'Jack' in Lorimer and Holland-Smith's (2012) case study; these coaches all reported long, on going involvement with adventure sports and the impact of significant role-models in the development of their values and beliefs in relation to adventure participation and coaching. Coach 2 stated: 'I think I'm always trying to encourage my students to embrace the adventure ... I'm sure it does run as a thread through my coaching because it's probably the most important reason for me why I do these things.' This long, ongoing involvement with adventure may lead to a tacit acceptance of the complexities involved with adventure sports. Personal successes and development in turn lead to a view of challenge as a positive aspect of life. Coach 4 commented: 'I don't see challenges as limiting factors. I see challenges as things to work towards.' Interaction with the environment, and therefore the associated challenge/risk, requires any potential learning to be highly contextual and reflect the dynamism, complexity and risks involved in having an adventure. This long involvement with and passion for adventure and challenge influenced the EC and was also manifest in the mental model of performance that the coaches aspire to instill in their students.

In this respect, the coaches were working towards a model of performance that is constructed and continually adapted to reflect the environment, individual and goal at hand. Coach 5 stated: 'That model would have been made up over 20-odd years of coaching ... that's still evolving. I'm not saying it's fixed because it's not.' Central to this mental model was the capacity for the student to be independent in the complex adventure setting. This necessitated a pedagogic approach and philosophy that was both learnercentered and highly differentiated. This approach reflects the personal nature of the learning process, perception of risk and its impact and a tacit acceptance of adventure as a personal construct.

\section{Independent performance}

As stated, the ASCs in this study all recognized independent performance as a long-term coaching goal, and this contributed to the aforementioned mental model. The parallel focus on technical and cognitive aspects of performance resulted in a considered and structured exposure to adventurous environments. This clear 'independent' performance target, rather than a high level of performance, was clearly the end goal. Coach 4 commented:

I want to get them to a place where they don't need me . . . by giving them the skills to function in the outdoors in terms of [the] technical skills they need, in terms of selfawareness

$$
\begin{aligned}
& \ldots \text { [awareness of] their environment and how they } \\
& \text { function in that environment as well. . . . [get them, the } \\
& \text { students] to a position where they could go away and have } \\
& \text { adventures and then come back in one piece. }
\end{aligned}
$$


Coach 1 highlighted the difficult balance and focus on psychological aspects of performance: 'I'm looking at the risk benefit analysis for the client . . . so they can be involved in the decision-making.' The decision-making element of independent performance facilitated the adaptability and flexibility that characterize the mental model. The pedagogic process exhibited a focus on lifelong learning, reflective practices and decision- making in addition to the technical skills. Accordingly, a holistic position was adopted to the student's development over a long period that did not assume direct contact with the ASC. Elements of performance, such as meta-cognition and meta-reflection, form key- stones of the cognitive skills developed alongside the technical skills. These multiple knowledge sources were synergized with developed and integrated reflective activity.

\section{Knowledge sources}

The desire to be 'as good as I can' (Coach 4) was complemented by a high degree of inaction and on-action reflection, as suggested by Coach 5: 'I'm constantly reflecting.' Coach 5 made the relationship explicit: 'I always strive to be as good as I can, really, and to get there by reflecting and getting feedback and tweaking, adapting what I do.' To facilitate this, the ASCs appear to draw on a broad range of different knowledge sources that are adapted to address the situational needs. The ASCs see this as a product of involvement within their own community of practice (CoP) (cf. Collins, 2013; Polyani \& Sen, 2009; Stoszkowski \& Collins, 2014).

Reflecting this, coaches placed value on interaction with fellow coaches. Working with other coaches was seen as a challenge, however. Coach 1 first stated that working with someone for the first time is a challenge, but then, in the same response, gave the following example:

... in the pool session yesterday, I have a kind of methodology that I work within the pool and my colleague's got his methodology. And coming together, I think, oh, that's a really good idea, and he's nicked things of mine and I nicked things of his.

Coach 1 described the CoP and its role in broader terms:

The opportunity to work with a lot of colleagues and peers and people I highly respect, and gain knowledge from associating with them, from working with them, from discussing things with them. So, I think, if you'd like to call it a support network of other people, or a developmental network ...

Coaches 6 and 7 independently discussed their working interaction. The following view was illustrated by Coach 6: 
We will spend a lot of time discussing what we've done and even sometimes, during courses, I'll be texting him, he'll be texting me ... that opportunity to benchmark to see, if we're still operating at that level and are we giving people the right information you know, other different ways to do things, so I think that benchmark is critical for us.

The ASCs in this study drew on the transferability of skills from other domains. Coach 5 highlighted that, within his discipline, 'the broader that I've looked into paddle sport myself and coaching it, the narrower it seems to get ... It's boats and water and the environment moves . . . what causes it [to] move is just slightly different.' Coach 3 alluded to this as attitudinal, suggesting: 'I'm a little bit obsessive about trying to find why somebody's coaching worked.' All of the participants recognized this inherently inquisitive approach.

These elements - inquisition, experimenting and application-were made possible by an integrated reflective practice. This process was, in turn, motivated by the desire to be as good as possible. Interestingly, this was seen as an inevitable and essential feature of coaching and performance. Coach 3 commented on the integration of on-action reflection in general:

... when reflective practice became the buzzword, however long [ago] that was, and I go, 'Okay, now you must be reflective'. The reason why I think I've sort of fought back against it was ... 'Why [are] you making such a big deal of this? It's what you do isn't it?' If somebody wants to be a good coach or a good paddler, they finish whatever it is they're doing and they sit back and think of what went well and what they could do better. That's just normal, to my mind. But clearly it's not everybody's.

For ASCs, reflective practice was a sine qua non. The close integration of reflective activity into coaching practice may stem from the long engagement with adventure sport for which PJDM and its associated in-action and on-action reflective activities are central.

\section{Adaptability and flexibility}

There was recognition that the complexity of the ASC process requires the practitioner and coach to be able to make decisions and act on them both in-action and on-action. The specific interaction of environment, individual and task forms the key components; the potential link with ecological psychology and dynamical systems approaches (Davids, Button, \& Bennett, 2008) is inescapable. The judgments required in the utilization of the three components placed a high PJDM load on the ASC, with alteration of the three 
components utilized to create variety and randomness in the practice from an early stage. The pedagogic approach is, of necessity and by design, flexible and adaptive: firstly, to optimize the use of the environment; and secondly, to respond to the individual's reaction in that environment. Coach 1 commented on the PJDM load: 'I'm having to juggle umpteen different things. I'm looking at the overall safety of something. I'm looking at the risk benefit analysis for the client, what level are they at, so can they be involved in the decision-making.' In a similar fashion, Coach 5 suggested that 'I can stretch people on easier water and make it more challenging for them' and later stated: 'That's the crucial bit for adventure sport coaching; it's that I've got to manage that environment.' Illustrating this key skill for the ASC, Coach 1 described the issues further: 'On a mirror calm day, you might as well be in a nice, safe gymnasium, the risk is incredibly minimal'comparing this with 'day one with clients [novice] in canoe and you decided to run down a lake in the force four-five ... so you actually put them into an incredibly adventurous environment.' Coach 3 drew on his experience in competitive paddle sport to state:

... the pressure to make good decisions as an adventure sports coach are much higher than even at world championship competition level because the consequences are physical and real

... If I make the wrong decision working out [in an adventure context] with my group then somebody could get hurt or worse, whereas if I make a bad decision coaching [at] the world championships, I [meaning the athlete] don't get to stand on the highest point on the wooden block, is essentially what it comes down to.

Against these demands, the PJDM process enabled the adaptability and flexibility required by both the coach and performer to be able to respond to the challenges associated with adventure sports. Clearly, the cognitive load plays a significant part in the ASC process. Supporting this, Coach 3 stated experiencing 'definitely more decisionmaking with the adventure side of it.'

\section{General Discussion}

Building on the literature base provided earlier in the paper, this investigation sought to unpack and articulate the EC within ASC practice. Do expert ASCs have an identifiable EC that can be recognized throughout their practice and, if so, can it be articulated? The applications and impact of EC research are then considered and further avenues for research are proposed.

\section{Do expert ASCs have an identifiable epistemological/ontological chain?}

Evidence from this study supports the notion that an EC does exist in adventure sports coaching, as in other domains (cf. Buehl \& Fives, 2009; Hofer, 2002; Kang, 2008; Thorburn \& Collins, 2003), and provides the 'scaffolding' that underpins the PJDM process which synergizes the ASC's practice. The dendritic and complex nature of adventure sports coaching and, in particular, the PJDM associated with it (Collins \& 
Collins, 2013) would appear best supported by an ontological chain/EC rather than formulaic models. This EC is utilized within the CoP to promote discussion and knowledge generation/exchange, which may in turn lead to an understanding of a shared ontological chain/EC. Throughout the EC, the ASCs utilize reflective practice, explore a broad range of knowledge sources, audit an exploratory 'straw man' structure and employ an almost experimental approach to coaching that aims to create an independent, adaptive and flexible performance (cf. Schön, 1983). This approach aligns with deeply held values and beliefs that relate to the knowledge, learning and challenges that stem from a long, formative involvement with 'adventure.'

\section{Can the epistemological chain be recognized throughout adventure sport coaching practice?}

The ASCs in this study did articulate the links between the EC and the coaching process. The ASCs were able to support these links with clear examples based on personal experience and reflection (cf. case-based reasoning; Hoffman, 1996). Inconsistencies between practice and the EC were based on responses to the environment and direct safety concerns that override any philosophical position. The perceived benefit does not override the potential for injury or death.

The ASCs in this study all exhibited many of the characteristics associated with definitions of expert practice (cf. Collins, 2013; Collins \& Evans, 2009; Fazey, Fazey, \& Fazey, 2005; Shanteau, 1992; Sternberg, 2003; Tozer, Fazey, \& Fazey, 2007) and high- level coaching practices: the significant factor being the contextualization of the inter- personal and intrapersonal aspects of expertise. Their pedagogic behaviours placed value on generating long-term, autonomous performance (athlete/student focused) in context via constructivist approaches. The ASCs recognized the professional nature of their responsibilities; however, they appeared reluctant to be described as 'expert' — as Coach 6 stated, 'there [is] always more to learn.'

\section{Can the epistemological chain be articulated?}

It was evident from the interviews that the ASCs placed great value on the interaction within their $\mathrm{CoP}$ and that, despite being very highly qualified, they felt they gained most from being in practice, interaction with peers and recognizing the value of key rolemodels in their development. Clearly the EC can be articulated and this shared experience of adventure and coaching creates camaraderie within the CoP. Notably, this cadre has a common language and shared specialist tacit knowledge (Collins \& Evans, 2009) as part of the continuous development that characterizes these ASCs in practice. This non-formal learning (Boud \& Middleton, 2003) is linked with a refined and integrated reflective practice that is involved both in-action and on-action (Schön, 1983).

\section{Implications and limitations}

In this sample, a student-centered, adventurous EC became apparent. Within this sample, the EC played a significant part in expert practice. Is this actually an EC or, given the early and long-term exposure to 'adventure,' may this be better described as an ontological chain, presumably being based in the ASCs' view of the world as a challenging place? Did the ontological chain make them good or did the EC come from exposure to the tacit knowledge held within the CoP, personal high-level practice, adventure sports 
participation and reflective activity? Clarification of this issue awaits further investigation. In accepting this EC, it appears sensible to develop potential coaches along these lines, namely to establish and utilize a belief structure espoused by the certifying body or based on further study of expert practice in single disciplines. Evidence from other domains points to the fact that the significance of the EC is not unique in this regard (cf. Grecic \& Collins, 2013). However, the significance of the long and formative experiences reported before coaching involvement for the ASCs in both this study and that of Lorimer and Holland-Smith (2012) may provide insight into a unique element of ASC practice; namely, the possibility of an ontological underpinning in addition to the epistemological.

Continuing on from the sophisticated EC (Schommer, 1994), it would be worthwhile to consider how ASCs construct the declarative knowledge required for both technical and coaching performance and what constitutes an expert in these dynamic fields. Investigation of the traits that generate ASCs who are capable of operating under the risk pressures associated with adventure sports would also seem merited.

The coaches in the sample all demonstrated a 'growth mind-set' (Dweck, 2004). This trait, along with an integration of reflective activity into both the coaching and technical performance, generates willingness and a technical skill set that enables them to experiment (and learn from both success and failure), adapt and overcome day-to-day ASC coaching challenges, such as the environment's impact on performance. Comprehension of this aspect of expert ASC practice and its integration with the learning environment, the PJDM process and the ASC roles remains an avenue for further investigation.

\section{Conclusion}

The ASCs in this study demonstrated a sophisticated EC that supports their coaching and PJDM practices. The manifestation of this EC, its value and extent, combined with the nature of the reflective practices that support it, is worthy of further research across a range of adventure sports, levels of experience and sample sizes. In particular, the integration of the EC, PJDM and reflective activity into practice will be critical in designing effective ASC education programs. This raises the following questions: what is the impact of this on ASC practice and education; are the coaches actually operationalizing this EC; and is this actually beneficial to the student in the short, mid and long term?

The value of the CoP as a source of knowledge is valued and recognized by the ASCs in the study. The implication and integration of the CoP into ASC education programs, and the resultant exposure to the specialist tacit knowledge held within the CoP, will provide opportunities for investigation. The CoP and the significance of the NGB, peers or performers will require clarification.

In short, noting the restrictions of generalizing these findings, evidence from this study supports the notion that a sophisticated EC of beliefs exists in adventure sports coaching, as it does in other domains (cf. Buehl \& Fives, 2009; Hofer, 2002; Kang, 2008; Thorburn $\&$ Collins, 2003). This EC provides the 'scaffolding' that underpins the PJDM process which synergizes the ASC's practice. The exact nature of this chain as exclusively epistemological or ontological will be a source for debate and/or further research. However, it is clear that this scaffolding acts to support the auditing process by which the ASCs judge the success of their coaching process. 


\section{References}

Boud, D., \& Middleton, H. (2003). Learning from others at work: Communities of practice and informal learning. Journal of Workplace Learning, 15(5), 194-202. doi:10.1108/13665620310483895

British Mountaineering Council (BMC). (2003). Participation statistics. Manchester, UK:

Buehl, M., \& Fives, H. (2009). Exploring teachers' beliefs about teaching knowledge: Where does it come from? Does it change? The Journal of Experimental Education, 77(4), 367-408. doi:10.3200/JEXE.77.4.367-408

Collins, D., Abraham, A., \& Collins, R. (2012). On vampires and wolves - exposing and exploring reasons for the differential impact of coach education. International Journal of Sports Psychology, 43(3), 255-271.

Collins, H. (2013). Three dimensions of expertise. Phenomenology and the Cognitive Sciences, 12(2), 253-273. doi:10.1007/s11097-011-9203-5

Collins, H., \& Evans, R. (2009). Rethinking expertise. London, UK: University of Chicago Press.

Collins, L., \& Collins, D. (2012). Conceptualizing the adventure-sports coach. Journal of Adventure Education and Outdoor Learning, 12(1), 81-93. doi: 10.1080/14729679.2011.611283

Collins, L., \& Collins, D. (2013). Decision-making and risk management in adventure sports coaching. Quest, 65(1), 72-82. doi:10.1080/00336297.2012.727373

Davids, K., Button, C., \& Bennett, S. (2008). Dynamics of skill acquisition: A constraints led approach. Champaign, IL: Human Kinetics.

Dweck, C. S. (2004). Mindset: The new psychology of success. New York, NY: Random House. Fazey, I., Fazey, J. A., \& Fazey, D. M. A. (2005). Learning more effectively from experience. Ecology \& Society, 10(2), 4. Retrieved from http://www.ecologyandsociety.org/vol10/iss2/ art4/

Grecic, D., \& Collins, D. (2013). The epistemological chain: Practical applications for sport. Quest, 65(2), 151-168.

Hofer, B. K. (2002). Epistemological worldviews of teachers: From beliefs to practice. Issues in Education, 8(2), 167-174. doi:10.1891/194589503787383109

Hoffman, R. R. (1996). How can expertise be defined? Implications of research from cognitive psychology. In R. Williams, W. Faulkner, \& J. Fleck (Eds.), Exploring expertise (pp. 81-100). Edinburgh, UK: University of Edinburgh Press.

Howard, B. C., McGee, S., Schwartz, N., \& Purcell, S. (2000). The experience of constructivism: Transforming teacher epistemology. Journal of Research on Computing in Education, 32(4), 455-466. 
Kang, N. (2008). Learning to teach science: Personal epistemologies, teaching goals, and practices of teaching. Teaching \& Teacher Education, 24(2), 478-498. doi:10.1016/j.tate.2007.01.002

Lorimer, R., \& Holland-Smith, D. (2012). Why coach? A case study of the prominent influences on a top-level UK outdoor adventure coach. The Sports Psychologist, 26, 571-583.

Nash, C., Martindale, R., Collins, D., \& Martindale, A. (2012). Parameterising expertise in coach- ing: Past, present and future. Journal of Sports Sciences, 10, 985-994. doi:10.1080/ 02640414.2012.682079

National Coaching Foundation (NCF). (2010). UKCC level 1 guide. Headingley, UK: Author.

Perry, W. G. J. (1981). Cognitive and ethical growth: The making of meaning. In A. W. Chickering (Ed.), The modern American college (pp. 76-116). San Francisco, CA: Jossey-Bass.

Polyani, M., \& Sen, A. (2009). The tacit dimension (Re-issue ed.). Chicago, IL: University Of Chicago Press.

Royal Yachting Association (RYA). (2009). Water-sports and leisure participation survey. Hampshire, UK: Author.

Ruse, D., \& Collins, L. (2005). Canoe and kayak games: 250 best paddle sport games (4th ed.).Penrith, UK: River Publishing.

Schommer, M. A. (1994). Synthesizing epistemological belief research: Tentative understandings and provocative confusions. Educational Psychology Review, 6, 293-319. doi:10.1007/ BF02213418

Schon, D. (1983). The reflective practitioner: How professionals think in action. New York, NY: Basic Books.

Schraw, G. J., \& Olafson, L. J. (2008). Assessing teachers' epistemological and ontological world- views. In M. S. Khine (Ed.), Knowing, knowledge and beliefs: Epistemological studies across diverse cultures (pp. 25-44). Dordrecht, The Netherlands: Springer.

Shanteau, J. (1992). Competence in experts: The role of task characteristics. Organizational Behavior and Human Decision Processes, 53, 252-266. doi:10.1016/0749-5978(92)90064E

Smith, J. A. (2011a). Qualitative psychology: A practical guide to research methods (2nd ed.). London, UK: Sage.

Smith, J. A. (2011b). Evaluating the contribution of interpretive phenomenological analysis. London, UK: Sage.

Smith, J. A., Flowers, P., \& Larkin, M. (2009). Interpretive phenomenological analysis. London, UK: Sage. 
Smith, J. A., \& Osbourne, M. (2008). Interpretive phenomenological analysis. In J. A. Smith (Ed.),

Qualitative psychology: A practical guide to research methods (pp. 53-80). London, UK: Sage.

Sparkes, A. C. (1998). Validity in qualitative inquiry and the problem of criteria: Implications for sport psychology. The Sport Psychologist, 12(4), 363-386.

Sports Coach, U. K. (2011). Sports coaching in the UK III: A statistical analysis of coaches and coaching in the UK. Leeds, UK: Author.

Sternberg, R. J. (2003). Wisdom, intelligence and creativity synthesized. Cambridge, UK: Cambridge University Press.

Stoszkowski, J., \& Collins, D. (2014). Communities of practice, social learning and networks: Exploiting the social side of coach development. Sports, Education and Society, 19(6), 773-788. doi:10.19080/13573322.2012.692671

Thorburn, M., \& Collins, D. (2003). Integrated curriculum models and their effects on teachers' pedagogy practices. European Physical Education Review, 9(2), 185-209. doi:10.1177/ 1356336X03009002004

Tozer, M., Fazey, I., \& Fazey, J. (2007). Recognizing and developing adaptive expertise within outdoor and expedition leaders. Journal of Adventure Education and Outdoor Learning, 7(1), 55-75. doi:10.1080/14729670701349780 